Ensino, Saúde e Ambiente-V5 (2), pp. 13 -24, ago. 2012

\title{
O ROBÔ DE JÚPITER: O ENSINO DE CIÊNCIAS MEDIADO PELA FICÇÃO CIENTÍFICA
}

\section{LUCKY STARR AND THE MOONS OF JUPITER: THE SCIENCE EDUCATION MEDIATED BY THE SCIENCE FICTION}

\author{
Rosana Marques de Souza ${ }^{1}$ \\ Emerson Ferreira Gomes ${ }^{2}$ \\ Luís Paulo Piassi ${ }^{3}$ \\ ${ }^{1}$ Escola de Artes, Ciências e Humanidades da USP, rosana.souza@usp.br \\ ${ }^{2}$ Instituto de Física da USP, emersonfg@usp.br \\ ${ }^{3}$ Escola de Artes, Ciências e Humanidades da USP, lppiassi@usp.br
}

\begin{abstract}
RESUMO
Este trabalho apresenta uma proposta de articulação do ensino de ciências com a literatura, neste caso, a série Lucky Starr, literatura infanto-juvenil de ficção científica escrita pelo escritor Isaac Asimov na década de 50 de acordo com os conhecimentos científicos da época. Apesar de alguns livros estarem desatualizados este fato não impede o uso da obra em sala de aula, pois auxiliará o trabalho do professor e incentivará o aluno a ter o hábito de leitura e de pesquisa sobre o assunto abordado no livro com o atual. O livro da série a ser focado neste trabalho é "O robô de Júpiter" que foi analisado e comparado com uma bibliografia mais recente, que nos mostrou que muitos dados do livro estão bem próximos dos atuais. Neste trabalho também apresentamos proposta de atividades com o livro e o resultado de sua aplicação em sala de aula.
\end{abstract}

Palavras-chave: literatura, ficção científica, ensino de ciências

\begin{abstract}
This paper presents a proposal for the use of literature in the science education, in this case, the Lucky Starr series, a science fiction series for young readers, wrote by the science fiction novelist Isaac Asimov in the 50's, according to the scientific knowledge of that time. Although some books are outdated this fact does not preclude use of the work in the classroom, because the teacher's work will assist and encourage the student to have the habit of reading and research on the subject addressed in the current book. The book of the series to be focused in this work is "Lucky Starr and the Moons of Jupiter" which was analyzed and compared with a recent literature about astronomy, which showed that many of the data book are very close to those present. This work also made proposals for activities with the book.
\end{abstract}

Key words: literature, science fiction, science education.

\section{INTRODUÇÃO}

No âmbito escolar sabemos que não apenas nas aulas de Língua Portuguesa a leitura é vista como requisito, mas em todas as demais disciplinas e diferentes níveis de escolaridade exige-se que os alunos saibam ler e interpretar informações referentes a 
determinado assunto. Em uma aula de ciências é de costume o professor exigir que seus alunos leiam determinado artigo, alguma matéria científica ou jornalística, ou simplesmente explore o livro didático ou apostila para explicar o conteúdo proposto. Outros professores optam pelos métodos tradicionais, escrevendo as informações na lousa. Os alunos copiam a matéria, porém não sabemos se compreendem o que lêem. Pinto (2007, p. 22) afirma que os livros didáticos e materiais de divulgação cientifica não são recursos didáticos idênticos, pois possuem finalidades diferentes, sendo organizados de maneiras diferentes sem necessariamente ter o mesmo público alvo, mas as escolas que optam em trabalhar com materiais de divulgação científica nem sempre dão ênfase a esse detalhe. Por estes motivos, percebe-se que no ensino de ciências há a necessidade de educar os alunos cientificamente, para que estes possam entender e interpretar informações divulgadas nos diversos meios de comunicação, pois a ciência como conhecimento está em toda parte e possui fundamental importância na compreensão dos fenômenos naturais e na construção das demais áreas do conhecimento tanto científicos como culturais.

Nesse trabalho utilizaremos a literatura, mais precisamente a infanto-juvenil para ensinar ciências de forma que possamos incentivar os alunos à leitura e a pesquisa, estimulando o debate e saindo da rotina tradicional do ensino, mostrando que é viável articular essas duas áreas do conhecimento de forma a permitir a compreensão por parte dos alunos. Zanetic (2006, p. 67) acredita que é possível e desejável essa articulação e mostra em vários exemplos como autores clássicos da literatura universal podem estar presentes nas aulas de ciências. De acordo com Martin-Diaz (1992, p. 18), que usa contos de ficção científica para ensinar física, "a literatura contém numerosas sugestões sobre como, no contexto da educação científica escolar, a motivação dos estudantes para aprender pode ser estimulada". A ficção científica traz assuntos contemporâneos muito ricos em conceitos ligados às ciências naturais. Esse tipo de literatura, porém, não trata apenas de ciência, mas também das relações humanas:

\footnotetext{
A ficção científica isto deve ser claramente entendido, não é ficção sobre ciência. É sobre pessoas, como é toda ficção - apesar de que nesse caso especial, elas podem bem não ser humanas - beneficiadas ou afligidas pelo impacto das mudanças técnicas (BRUNNER, 1971, p.389).
} 
A ficção científica como gênero literário aborda a informação em tempo real, ou seja, os dados apresentados pela ciência, e o imaginário, representados por atos ficcionais, como afirmam Gomes-Maluf \& Souza (2008):

No tempo real é apresentado ao público o que na Ciência se discute atualmente e quais os direcionamentos apresentados pelas novas pesquisas; e em tempo imaginário, a ficção científica transforma o caminhar das pesquisas científicas em "futuro possível", oferecendo a possibilidade de se fazer Ciência, antecedendo os resultados a serem alcançados (GOMES-MALUF \& SOUZA, 2008, p. 280).

Nesse sentido é possível que como recurso didático, a literatura de ficção científica relacione os fatos estudados pela ciência, utilizando o imaginário como processo de construção do pensamento científico.

O objetivo desse trabalho é verificar se a série Lucky Starr de Isaac Asimov tem potencial para ser usada como instrumento didático não somente para ensinar conceitos científicos, mas também para abordar temas mais gerais relacionados aos problemas e situações atuais vividos pela sociedade, ao passo que auxilie os alunos a compreenderem fatos científicos e os distinguem dos ficcionais e facilite o trabalho do professor em selecionar a literatura adequada para ensinar o que é proposto com a necessidade de educar os alunos cientificamente.

O conteúdo do livro será analisado, com o intuito de verificar os pontos que foquem a ciência, principalmente em relação ao conhecimento da astronomia. Após a análise, propostas de atividades serão elaboradas e aplicaremos uma delas em sala de aula para checar como os alunos encaram esse tipo de atividade e que tipos de resultados podemos obter.

\section{POR QUE ISAAC ASIMOV?}

Isaac Asimov é considerado um dos melhores escritores de ficção científica. Nascido na Rússia em 1920, aos 17 anos já tinha certeza que seria um escritor (ASSIS, 2005, p. 52). Apesar em 1948 recebeu seu Ph. D em bioquímica pela mesma universidade (ASSIS, 2005, p. 54). Sua vida o guiou em muitas direções, chegou a lecionar, porém jamais deixou sua paixão de lado.

Asimov escrevia ficção científica pensando no futuro. Foi a primeira pessoa a utilizar a palavra robótica em um texto impresso publicado em março de 1942 na revista Astounding Science Fiction, mas já escrevia sobre robôs desde os seus 19 anos 
(ASIMOV, 1991, p. 7). A trilogia da Fundação (Fundação, Fundação e Império e Segunda Fundação) recebeu o prêmio Hugo em 1966, e é considerada uma das melhores séries de F.C.

Hoje a ciência avançou de tal forma que saudou Asimov como "profeta" pois muitos artifícios tecnológicos usados em suas obras são "invenções" formuladas pela sua imaginação e foram previstas anos antes de se tornarem realidade. No conto "Sally" (1953) há a descrição de carros computadorizados quase dotados de vida própria, e nos últimos anos já existem carros computadorizados que conversam com seus motoristas (ASIMOV, 1991, p. 9 e 10).

Asimov pretendia escrever 500 livros, mas chegou aos 463, porém sua obra geral soma 509 obras em sua bibliografia. O autor mesmo sendo bioquímico, entendia sobre ciência, particularmente astronomia.

\section{POR QUE A SÉRIE LUCKY STARR?}

A série Lucky Starr foi escrita entre os anos de 1952 a 1958, para o público infanto-juvenil. São seis livros que apresentam aventuras espaciais, mistério, suspense, curiosidades e heroísmo, e assim podem ser classificados como space opera, que segundo Tavares (1992, p. 09):

Essas histórias de aventuras espaciais localizadas num tempo futuro ou nos confins do universo; uma fantasia tecnológica onde há muita ação e muita descrição, e se trabalha com personagens e situações fortemente estereotipados, e por isso mesmo facilmente reconhecíveis.

Para Fiker (1985, p.18), essa série é composta por aventuras banais e juvenis, eminentemente didáticas servindo de veículo para iniciação científica.

Asimov descreveu suas aventuras em vários planetas do sistema solar. Porém, com o avanço dos métodos de pesquisa o conhecimento sobre o sistema solar também sofreu enormes mudanças. Visto que muitas das descrições dos planetas feitas por Asimov na época, tornaram-se ultrapassadas, o autor reconhece que várias das descrições existentes são baseadas em dados dos conhecimentos existentes na época, e que hoje estão desatualizadas. Fez questão de acrescentar notas explicativas quando a série foi reeditada nos anos 70, mostrando-se preocupado em não passar informações incorretas a leitores com poucos conhecimentos do assunto, identificando alguns equívocos do conhecimento astronômico na época em que a obra foi escrita (ASIMOV, 1980). Esse fato, porém, não invalida as possibilidades didáticas da obra, pois acreditamos que o professor de ciências poderá usar a série Lucky Starr para ensinar 
astronomia aos seus alunos comparando as informações contidas nos livros com a ciência astronômica atual.

Asimov afirma que o único livro da série que permaneceu correto em termos científicos foi Vigilante das Estrelas, porém, esses fatos não prejudicaram as vendas da série, (ASIMOV, 1991, p. 11 e 12) que é composta dos seguintes títulos:

David Starr Space Ranger - As Cavernas de Marte (1952). A Terra importa alimentos de Marte e as pessoas que ingeriam esses alimentos morriam misteriosamente em menos de cinco minutos (ASIMOV, 1971).

Lucky Starr and the Pirates of the Asteroids - Vigilante das Estrelas (1953). Lucky quer descobrir e se vingar de quem assassinou seus pais. Para isso ele se infiltra entre os piratas que viviam no cinturão de asteróides (ASIMOV, 1976).

Lucky Starr and the Oceans of Venus - Os Oceanos de Vênus (1954). Em uma visita a Vênus, Lucky e Bigman descobrem que há algo misterioso capaz de controlar a mente das pessoas (ASIMOV, 1978).

Lucky Starr and the Big Sun of Mercury - O Grande Sol de Mercúrio (1956). Em um ambicioso projeto com o intuito de controlar a luz solar, Lucky e Bigman vão a Mercúrio desvendar uma misteriosa sabotagem (ASIMOV, 1972).

Lucky Starr and the Moons of Jupiter - O Robô de Júpiter (1957). Com o dispositivo antigravitacional Agrav, a Terra estava prestes a obter uma de suas maiores conquistas. Mas havia um espião tentando impedir esse feito (ASIMOV, 1981).

Lucky Starr and the Rings of Saturn - Os Anéis de Saturno (1958). O espião Agente $\mathrm{X}$ foge da Terra levando consigo uma cápsula com informações ultrasecretas que podem destruir o império terrestre (ASIMOV, 197?).

Os personagens são corajosos, respeitados e temidos. O herói David Lucky Starr é membro do Conselho de Ciência, uma organização poderosa e respeitada que combatia os inimigos do planeta Terra dentro e fora do Sistema Solar. Por sempre ter sorte em seus feitos, era chamado de Lucky, que significa afortunado.

John Bigman Jones é um marciano baixinho e rabugento. Com um metro e cinquenta e cinco de altura, detestava quando falavam de sua estatura. Com uma personalidade forte e marcante, era o companheiro inseparável de David. Assim, Lucky e Bigman eram como os mais bem conhecidos personagens Batman e Robin. 
A partir da criatividade do autor Isaac Asimov em caracterizar os personagens, percebe-se que a série Lucky Starr é uma leitura recomendável para o público jovem por ser atrativa cheia de suspense e mistério. A preocupação do autor em passar as informações e os conceitos científicos de forma correta com linguagem simples e com caráter didático foi perceptível em suas justificativas na década de 70 (ASIMOV, 1984, p. 61).

A série sendo utilizada como recurso didático em sala de aula proporcionará a interação da literatura infanto-juvenil e a ficção científica com as aulas de ciências, que atualmente estão diretamente vinculadas com a divulgação científica. Os alunos irão adquirir o hábito da leitura e da pesquisa ao analisarem os conceitos astronômicos abordados na série com os conhecimentos divulgados atualmente, e de certa forma auxiliará o trabalho do professor de educar seus alunos cientificamente conforme segue o conteúdo disciplinar exigido.

\section{O ROBÔ DE JÚPITER}

O Robô de Júpiter é o quinto livro da série e foi escrito em 1957. É uma aventura cheia de mistério e conceitos científicos. A aventura é cheia de suspense, mistério, disputa, desconfiança e ação. O respeitado Conselho de Ciência estava desenvolvendo uma tecnologia ultra secreta que iria beneficiar os avanços tecnológicos e progressos científicos terrestres. Esse projeto era chamado de AGRAV, e estava sendo desenvolvido e testado em Júpiter 9, um dos satélites de Júpiter. Porém havia suspeitas de espionagens. Os inimigos Sirianos queriam sabotar o projeto e arruinar os planos terrestres.

Diante dos seis livros que compõem a série vimos que todos possuem um relevante potencial didático para trabalhar conceitos de astronomia, biologia, física e química. O livro "O Robô de Júpiter" por ser cheio de mistério e aventura, além de ser o mais curto em número de páginas, foi selecionado para trabalharmos com um enfoque voltado com a astronomia, mais precisamente as características do planeta Júpiter e alguns de seus principais satélites. De acordo com o próprio autor muitos dados presentes nos livros que compõem a série estão desatualizados. Para sabermos se as informações desse livro estão de acordo com os conhecimentos atuais, foram selecionados alguns trechos que caracterizam Júpiter e seus satélites. Tais características serão comparadas com as informações contidas no livro "Astronomy Today" de Eric Chaisson e Steve McMillan, do ano de 1997. 


\section{CONCEITOS ASTRONÔMICOS DE “O ROBÔ DE JÚPITER”}

Asimov afirma na obra que "Júpiter era um disco grande o bastante para revelar suas zonas coloridas" (ASIMOV, 1981, p. 10), principalmente sua "grande mancha vermelha" (ASIMOV, 1981, p. 101). Essa descrição do autor entra em conformidade com as afirmações de Chaisson e McMcMillan, que descrevem que Júpiter "é dominado" por nuvens de diferentes cores, por conta dos diferentes "compostos químicos" que compõem essa atmosfera - compostos de fósforo e enxofre principalmente - e que quando "observamos muitas cores de Júpiter, na verdade estamos olhando para as diferentes profundidades na atmosfera do planeta”, neste caso a "Grande Mancha Vermelha, parece ser um furacão do tamanho da Terra que tem persistido por centenas de anos" (CHAISSON \& McMILLAN, 1997, p.236 e 237).

Os estudos recentes afirmam que as cores de Júpiter estão associadas a atmosfera turbulenta e pela presença de elementos químicos não compreendidos completamente. As cores do planeta descritas por Asimov estão de fato muito próximas das cores citadas pela referência.

Asimov cita os quatro grandes satélites Io, Europa, Ganimedes e Calisto e os demais numerados até doze conforme eram sendo descobertos (ASIMOV, 1981, p. 26). A bibliografia mais recente afirma que Júpiter tem muitas luas, com uma ampla gama de tamanhos e propriedades, semelhante a um sistema solar em miniatura. Suas quatro maiores luas, os satélites galileanos - Io, Europa, Ganimedes e Calisto - são cada um de tamanho comparável ao da Lua da Terra. (CHAISSON \& McMILLAN, 1997, p.234 e 243).

- Agora consideremos Júpiter. Mede cerca de quatrocentos e quarenta mil quilômetros na linha do equador, onze vezes a circunferência da Terra, embora sua rotação em torno de seu eixo dure apenas dez horas; cinco minutos menos, para sermos exatos. Um ponto em seu equador move-se a uma velocidade de aproximadamente quarenta e cinco mil quilômetros por hora, ou vinte e oito vezes mais rápido que qualquer ponto na Terra. Há a presença de uma poderosa força centrífuga e um abaulamento equatorial maior ocorre então, especialmente devido ao fato de que o material que compõe as camadas mais externas de Júpiter é mais leve que aquele que compõe a crosta terrestre. O diâmetro de Júpiter, em seu equador, mede aproximadamente nove mil e seiscentos quilômetros mais que seu diâmetro Norte-Sul. A diferença entre diâmetros é de quinze por cento, e isso pode ser facilmente observado (ASIMOV, 1981, p. 95). 
Como com outros planetas, pode-se tentar determinar a taxa de rotação de Júpiter, simplesmente pelo tempo que uma característica de superfície se move ao redor do planeta. No entanto, no caso de Júpiter (e, certamente, todos os planetas gasosos exteriores), existe uma captura - Júpiter não tem superfície sólida. Tudo o que vemos são características de nuvens na atmosfera do planeta. Ao contrário da atmosfera da Terra, diferentes partes da atmosfera de Júpiter, sem superfície sólida para "amarrá-los para baixo", se movem independentemente. Observações visuais e de deslocamento Doppler das linhas espectrais provam que as zonas equatoriais giram um pouco mais rápido (9 h 50 m período) do que nas latitudes mais elevadas ( 9 h 56 m período). Assim, Júpiter apresenta rotação diferencial - a taxa de rotação não é constante a partir de um local para outro. A rotação diferencial não é possível em objetos sólidos como os planetas terrestres, mas é normal em corpos como Júpiter. As zonas equatoriais giram mais rapidamente. Na verdade, Júpiter tem a rotação mais rápida de qualquer planeta do sistema solar. Nos objetos, como Júpiter, que são compostos de gases, as taxas de rotação elevadas podem produzir uma saliência bastante acentuada. $\mathrm{O}$ raio equatorial de Júpiter $(71400 \mathrm{~km})$ excede seu raio polar $(66800 \mathrm{~km})$ em cerca de 6,5 por cento (CHAISSON \& McMILLAN, 1997, p.234, 235 e 236).

O período de rotação do planeta citado por Asimov coincidiu com os dados mais recentes. Também coincidiu a relação das zonas equatoriais com a velocidade de rotação influenciada pelas diferenças de composição, Júpiter, no caso é mais leve, gira mais rápido e possui o equador mais acentuado de nuvens de gás. Não coincidiram as informações sobre o diâmetro equatorial do planeta. A região equatorial é maior que a região dos pólos em ambas informações, segundo Asimov a diferença entre os diâmetros é cerca de $15 \%$, e a bibliografia mais recente afirma que é $13 \%$.

Asimov descreve Io com tamanho quase igual ao da Terra, sua distância de Júpiter era de $455.000 \mathrm{~km}$, ou pouco maior do que a distância da Lua à Terra (ASIMOV, 1981, p. 98). A bibliografia mais recente afirma que Io é mais semelhante a nossa Lua. A distância do satélite ao planeta está bem aproximada Io orbita muito perto de Júpiter, apenas $422.000 \mathrm{~km}$, ou 5,9 raios de Júpiter, a partir do centro do planeta (CHAISSON \& McMILLAN, 1997, p.245 e 246).

A nave passara a cento e cinquenta mil quilômetros do Europa, cognominado de Júpiter Dois. Podia-se perceber marcas escuras do que outrora teriam sido 
Ensino, Saúde e Ambiente-V5 (2), pp. $13-24$, ago. 2012

cordilheiras. Os telescópios da nave provaram que lá existiram realmente. Lembravam as de Mercúrio, e não havia sinais da existência de crateras semelhantes às da Lua. Havia áreas de brilho intenso, também, lembrando geleiras (ASIMOV, 1981, p. 97).

A segunda lua de Júpiter é Europa, conforme citou Asimov. Possui rachaduras em sua superfície que são atribuídas à influência de maré de Júpiter e as forças gravitacionais de outros satélites do planeta. Essas rachaduras talvez sejam as marcas escuras de possíveis cordilheiras citadas por Asimov.

Sua superfície possui poucas crateras, sugerindo juventude geológica que indicam algum processo em curso que obliteram crateras de impacto assim que se formam. Alguns pesquisadores teorizaram que Europa está completamente coberto por um oceano de água líquida congelada. Essa teoria induz especulações sobre a probabilidade de vida nessa lua (CHAISSON \& McMILLAN, 1997, p.247). Com essas informações é possível deduzir que na época que Asimov escreveu a série já se tinham a noção de que Europa provavelmente possui gelo em sua superfície.

As informações citadas por Asimov estão de acordo com os dados recentes.

\section{PROPOSTAS DE ATIVIDADES}

Com o intuito de identificar a validade didática da série Lucky Starr, propomos algumas atividades utilizando o livro "O robô de Júpiter".

\section{ATIVIDADE 1: IMAGINANDO UMA RÃ-V.}

Usar um trecho do livro "O robô de Júpiter" para trabalhar a questão de Vida e Ambiente, um dos eixos temáticos propostos pelos PCN na área das Ciências Naturais (BRASIL, 1998), relacionando com a possibilidade da existência de vida fora do Planeta Terra.

Conteúdos: evolução, adaptação e condições para a existência de vida.

Os alunos leem o trecho do livro. O professor discute a possibilidade de vida fora do planeta Terra, e as características que esses seres teriam para se adaptarem as condições do planeta. Assim a discussão sobre a possibilidade de vida fora do nosso planeta, abordaria conceitos ligados à astronomia e biologia, uma vantagem de usar a literatura para relacionar as disciplinas. 


\section{ATIVIDADE 2: DIA E NOITE NO ESPAÇO?}

O trecho que será utilizado relata um diálogo entre o comandante Donahue e Lucky Starr que se aproximava com sua nave Shotting Starr de Júpiter 9. A intenção é poder discutir os movimentos de Revolução e Rotação nos planetas do Sistema Solar a partir da literatura e a ficção científica, relacionando com o eixo temático Terra e Universo, uma das propostas dos PCN para as Ciências Naturais (BRASIL, 1998).

Conteúdos: Conceito de dia astronômico, rotação e revolução de planetas em torno do Sol.

Após a leitura, o professor irá discutir o tema "Dia e Noite" em diferentes planetas de acordo com o movimento de Revolução e Rotação. Assim os alunos entenderão que os planetas são diferentes da Terra em muitos aspectos, como a distância até o Sol e o eixo de inclinação. Assim, a discussão poderá ser ampla e complementada com redações em grupo, pesquisas e seminários referentes ao assunto.

\section{ATIVIDADE 3: ECLIPSES EM EUROPA}

Fazer com que os alunos compreendam como ocorrem os eclipses. Normalmente apenas os eclipses envolvendo a Terra, Lua e Sol são tratados. Nessa atividade podemos mostrar que os eclipses podem acontecer em quaisquer planetas do Sistema Solar e seus satélites.

Conteúdos: Eclipses, movimento orbital dos satélites.

Pede-se para os alunos imaginarem que Europa tem um diâmetro de $3 \mathrm{~mm}$ e determinarem quais seriam, proporcionalmente, a distância entre Europa e Júpiter e o diâmetro de Júpiter (respectivamente $67 \mathrm{~cm}$ e $14 \mathrm{~cm}$ ). Os alunos confeccionam uma bolinha de papel com $3 \mathrm{~mm}$ de diâmetro e, usando uma bola de isopor de $14 \mathrm{~cm}$, fazem a simulação da órbita de Europa em torno de Júpiter, mostrando como ocorrem os eclipses.

O trecho que será utilizado apresenta uma descrição de como seria um eclipse em uma lua de Júpiter. Embora os dados apresentados no livro estejam desatualizados, a narração da estória permite ao aluno imaginar a situação. O uso de uma maquete permite com que o estudante visualize a descrição dada no livro. A comparação com os dados atuais permite ao aluno perceber que as informações apresentadas no livro estão 
desatualizadas, mas, ao mesmo tempo, perceber que o conhecimento científico não é absoluto, mas que vai sofrendo aperfeiçoamentos ao longo do tempo.

\section{CONSIDERAÇÕES FINAIS}

Nesses dois anos de pesquisa com a literatura infanto juvenil de ficção científica como a série Lucky Starr, é possível concluir que é viável e satisfatório relacionar as disciplinas que abrangem as ciências naturais tais como a física, a astronomia, biologia e química, com o encanto e o desenvolvimento da imaginação que a leitura proporciona. Também é possível utilizar a literatura para abordar temas relacionados com a realidade vivida pelos alunos e pela sociedade, como propõe os Parâmetros Curriculares Nacionais através dos Temas Transversais.

A série Lucky Starr por possuir uma linguagem clara e atrativa, prende o leitor que se envolve na aventura, suspense e mistério de cada obra. Além do entretenimento, o leitor irá se deparar com conceitos científicos que por mais difíceis se tornam fáceis graças à imaginação despertada.

O professor de ciências tem o trabalho de ensinar diversos conceitos em um período relativamente curto. Acreditamos que a série Lucky Starr auxiliará o docente a abordar tais conceitos, ao mesmo tempo em que prenderá a atenção e o interesse dos alunos. Dessa forma, os alunos perceberão a importância do desenvolvimento científico no progresso da humanidade, e muitas disciplinas consideradas "sem, sentido" e “chatas", por possuírem muitas fórmulas e cálculos, farão parte do cotidiano desses alunos de forma mais otimista e mais aceita.

Além do interesse pelas ciências, os alunos serão incentivados a terem o hábito da leitura em suas vidas, pois uma leitura como a série Lucky Starr apesar dos dados desatualizados, proporcionam a oportunidade para iniciar a educação científica através das pesquisas dos dados mais recentes, e com isso os alunos ficarão familiarizados com as exigências das universidades e consequentemente do mercado de trabalho.

Portanto acreditamos que é possível, necessário e viável articular obras de literatura na sala de aula para facilitar o trabalho do professor a ministrar sua disciplina, atraindo os alunos aos conteúdos. Não somente nas aulas de português que essa articulação deve ser feita, mas em todas as disciplinas, e não somente com a literatura de ficção científica, mas com toda abrangência que a leitura nos proporciona. 


\section{REFERÊNCIAS}

ASIMOV, Isaac. As cavernas de Marte. São Paulo: Hemus, 1971. . Vigilante das estrelas. São Paulo: Hemus, 1976. . Os oceanos de Vênus. São Paulo: Hemus, 1980. . Grande sol de Mercúrio. São Paulo: Hemus, 1972. .O robô de Júpiter. São Paulo: Hemus, 1981. . Os anéis de Saturno. São Paulo: Hemus, [197?] . No mundo da ficção científica. Rio de Janeiro: Francisco Alves, 1984. . Sonhos de robô. Rio de Janeiro: Record, 1991.

ASSIS, J. P. Exploradores do Futuro. Scientific American. Ed. Especial, n. 4, 2005. BRASIL. Ministério da Educação e do Desporto. Parâmetros Curriculares Nacionais: Ciências Naturais. Brasília: Secretaria da Educação Fundamental - MEC, 1998. BRUNNER, J. The educational relevance of science fiction. Phys. Educ. 6, Nov, 1971. pp. 389-391.

CHAISSON,E.\& McMILLAN, S. Astronomy today. New Jersey: Prentice Hall, 1997. CLARKE, A.C. 2010 Uma Odisseia no Espaço II. $4^{\text {a }}$ ED. Rio de Janeiro: Nova Fronteira, 1982.

GOMES-MALUF, M.C. \& SOUZA, A.R. A ficção científica e o ensino de ciências: o imaginário como formador do real e do racional. Ciência \& Educação, v. 14, n. 2, p. 271-282, 2008.

MARTIN-DIAZ, M. J. et al. Science Fiction comes into the Classroom: Maelstrom II. Phys. Educ. 27, 1992. pp 18-23.

FIKER, R. Ficção Científica: Ficção, Ciência ou uma Épica da Época? Porto Alegre: L\&PM, 1985.

PINTO, G.A. Divulgação científica como literatura e o ensino de ciências. Dissertação (Doutorado). São Paulo: Faculdade de educação da USP, 2007.

TAVARES, B. O que é ficção científica. $2^{\text {a }}$ Edição. São Paulo: Ed. Brasiliense, 1992. ZANETIC, J. Física e literatura: construindo uma ponte entre as duas culturas.

História, Ciências, Saúde - Manguinhos, Rio de Janeiro. V. 13 (suplemento), p. 55-70, outubro 2006. 